\title{
MAPPING STRUCTURE AND MORPHOLOGY OF SOLER GLACIER, IN NORTHERN PATAGONIA, CHILE, USING NEAR-VERTICAL, AERIAL PHOTOGRAPHS, TAKEN WITH A NON-METRIC, $6 \times 6$ CM-FORMAT CAMERA
}

\author{
by \\ Masuma Aniya \\ (Institute of Geoscience, University of Tsukubu, Ibaraki 305, Japan) \\ and
}

Renji Naruse

(Institute of Low Temperature Science, Hokkaido University, Sapporo 060, Japan)

\begin{abstract}
The surface structure and morphpology of the Soler Glacier, an outlet glacier located on the eastern side of the Patagonia Northern Icefield, were mapped and analysed, using near-vertical, aerial photographs, taken with a hand-held, $6 \times 6 \mathrm{~cm}$-format camera, in January, 1984. The major findings, which could hardly be obtained in the field, included identification of the five ice bodies and four sets of ogive patterns. The pattern and distribution of crevasses were also analysed. From the number and spacings of the ogives, the mean, annual, surface-flow rate was deduced to be about $100 \mathrm{~m}$ and $350 \mathrm{~m}$, at points $1.4 \mathrm{~km}$ and $6.6 \mathrm{~km}$ from the snout, respectively, with an average of $160 \mathrm{~m}$ for the middle reach.
\end{abstract}

\section{INTRODUCTION}

The use of aerial photographs, particularly vertical photographs, taken with a metric camera and coupled with ground controls, has long been recognized as one of the most efficient means of glacier mapping, because it provides a synoptic view of the glacier and enables detailed, photogrammetric measurements to be made (Haefeli 1966, Konecny 1966, Lliboutry and Reynaud 1981). However, this survey and mapping technique is not always practical or feasible, due to the cost and effort required in some glacier areas, where ground accessibility is very limited. Although the Patagonia Northern Icefield, Chile, is covered by trimetrogon photographs, taken in 1944-45, and vertical photographs, taken in 1974-75, the quality and scales of these photographs do not permit the detailed mapping of the glacier surface at large scales. Consequently, the aerial survey, with a hand-held, non-metric camera, pointing down through a bayhole of the airplane, was improvised to take near-vertical, overlapping, aerial photographs over the Soler Glacier, where we spent one month for the ground work in December, 1983. The purpose of this paper is to illustrate how effectively such aerial photographs can be used for glacier mapping.

\section{STUDY AREA: SOLER GLACIER}

This is an outlet glacier, located on the eastern side of the Northern Icefield around $46^{\circ} 54^{\prime} \mathrm{S}$ and $73^{\circ} 11^{\prime} \mathrm{W}$ (see inset Fig.2). It is a temperate, valley glacier about $7 \mathrm{~km}$ long and $1.5 \mathrm{~km}$ wide, with an area of about $12 \mathrm{~km}^{2}$. The elevation ranges from $350 \mathrm{~m}$ at the snout to $750-850 \mathrm{~m}$ at the base of icefalls and cliffs, through which ice from the icefield and the Cerro Hyades slope spills into the valley.

The topographic map covering this area on a scale of 1:50 000, with a $50 \mathrm{~m}$ contour interval, was produced in 1982 by the Instituto Geografico Militar of the Chilean government, from the 1974-75, vertical, aerial photographs of about 1:60000 scale.

\section{AERIAL SURVEY}

A bayhole, $80 \mathrm{~mm}$ in diameter, was installed in a single-engined Cessna 182, to accomodate vertical photographing. A $6 \times 6 \mathrm{~cm}$-format camera body (Zenza Bronica, SQ-Am), equipped with automatic exposure and motor drive, was employed, along with a standard lens ( $F . L=80$ $\mathrm{mm}$ ). A fast film, Kodak Ektachrome EPD 220 (ASA 200), was used to allow a larger aperture opening $(F=11)$ and fast shutter speed.

The glacier and icefalls were covered by several flights, at a cruising speed of $200 \mathrm{~km} / \mathrm{h}$ and $3200 \mathrm{~m}$ above sea level, on January 11, 1984. The nominal scale of the photographs ranges from $1: 36000$ to $1: 39000$, with overlaps varying from $30 \%$ to $70 \%$. The stereoscopic analyses were carried out on the photographs, enlarged to about 1:8000 scale and a mosaic was prepared, at about 1:20000 scale (Fig.1). These scales were determined from the distance measured on the ground between the two control stations.

\section{MAPPING STRUCTURE AND MORPHOLOGY}

1. Surface Conditions and Accumulation Areas

Figure 2 shows major structural and morphological features, interpreted on the photographs. About the northern half of the glacier is covered with debris, while the southern half is composed of clean ice. The former is fed with ice from the south-eastern slope of the Cerro Hyades $(\sim 3000 \mathrm{~m})$, mainly through avalanching over the exposed rocks, whereas the clean ice comes from the ice field, through a big ice fall. The debris-covered area is lower than the clean part in the cross-profile.

The accumulation areas were estimated from the topographic map to be about $44 \mathrm{~km}^{2}$ : the icefield about 36 $\mathrm{km}^{2}$ and the Cerro Hyades slope about $8 \mathrm{~km}^{2}$. These areas can be further divided into five, with corresponding ablation bodies (Fig.2), distinguished from the ogive and crevasse patterns and surface reliefs, interpreted on the photographs.

\section{Ogives}

There are two, distinctive, ogive-pattern systems on the surface: one occupies about the northern quarter, while the other the southern three-quarters of the glacier. The northern part (B-1) consists mostly of wave ogives, starting from the base of a small ice fall from the Cerro Hyades slope. The southern part is composed of wave ogives at the upper reach and band ogives at the middle and lower reaches and actually consists of three sets of ogives, indicated by slightly off-set patterns, revealed upon close 


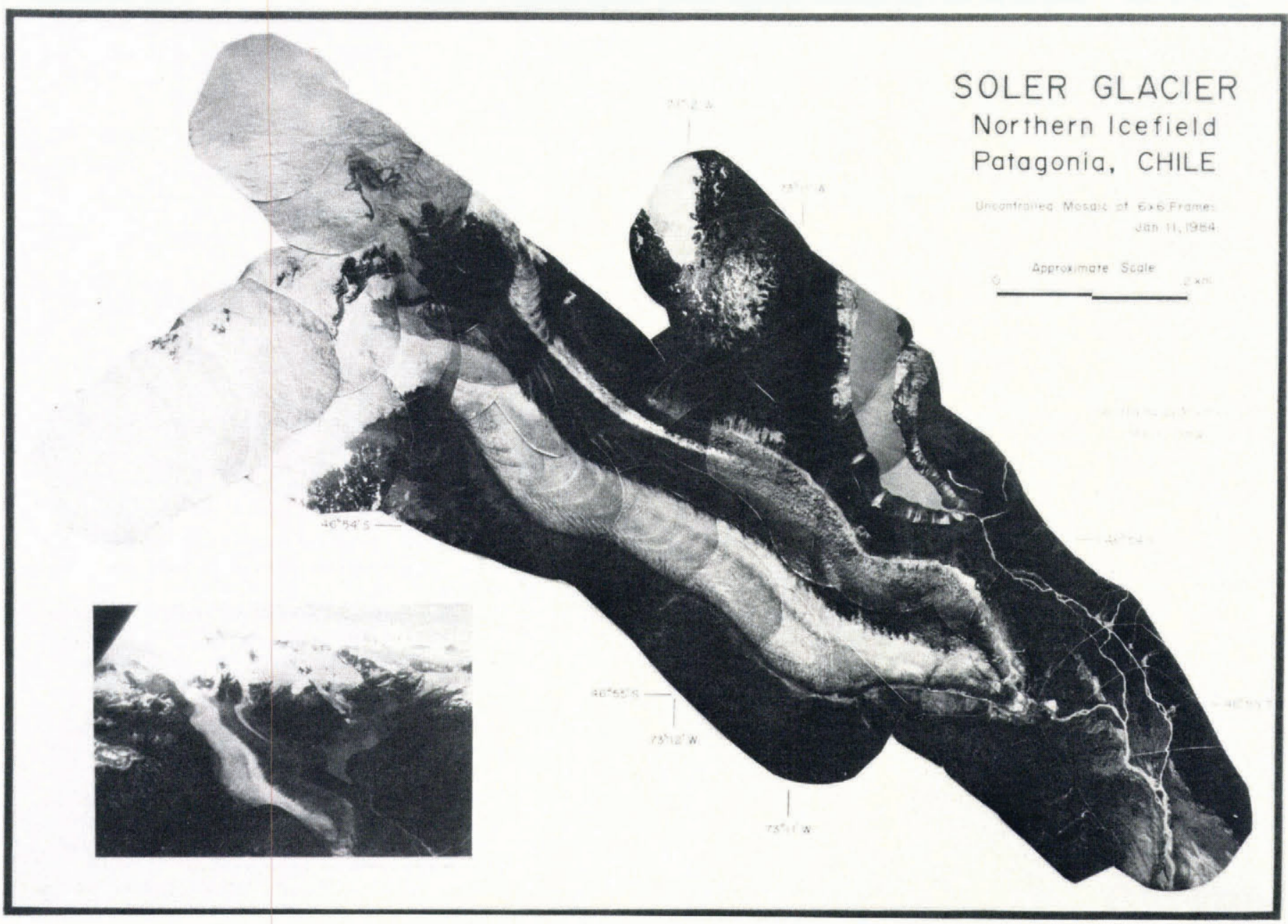

Fig.1. Mosaic of the Soler Glacier.

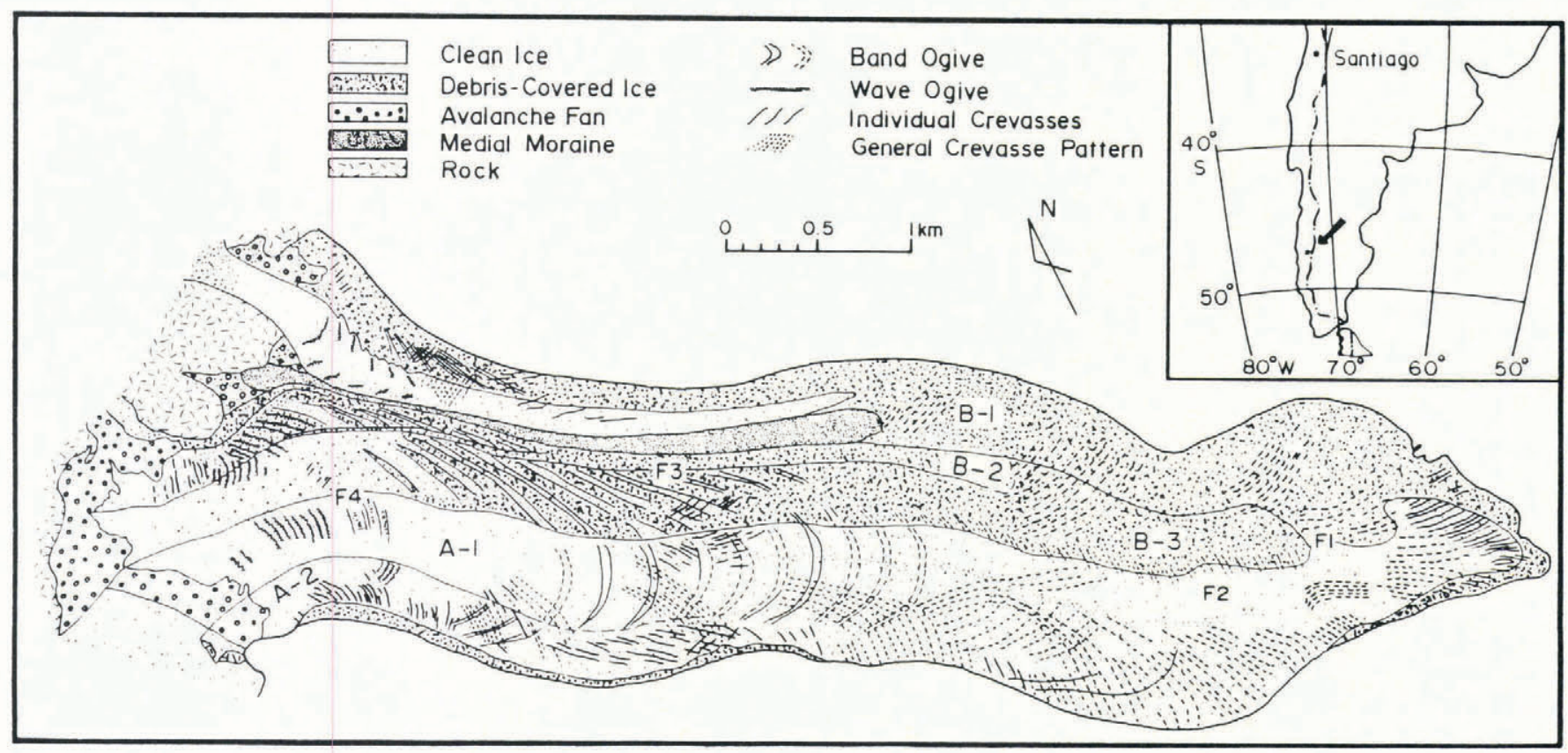

Fig.2. Surface structure and morphology of the Soler Glacier. F1, F2, F3, and F4 are the locations of the stakes, with which flow speeds were measured. A-1, A-2 (from icefield), B-1, B-2 and B-3 (from Cerro Hyades slope) are individual ice bodies. 
examination of the photographs. They originate from below an ice fall and/or an avalanche fan.

The band ogives of the B-3 body are best developed and can be traced all the way down to the point $1.4 \mathrm{~km}$ from the snout. There are 32 ogives in a distance of 5.1 $\mathrm{km}$. The distance between two, successive ogives can be taken as equivalent to the mean, annual, surface-flow rate at that position in a stable glacier (Haefeli 1966). The Soler Glacier can be regarded as stable (Aniya and Enomoto, in print) and, if it takes 32 years to cover $5.1 \mathrm{~km}$, the mean, annual, surface-flow speed would be about $160 \mathrm{~m}$.

Next, the spacings of the paired white and dark bands were measured and moving averages of three points were plotted against the distance from the snout (Fig.3). The curve can probably be taken as roughly indicating the

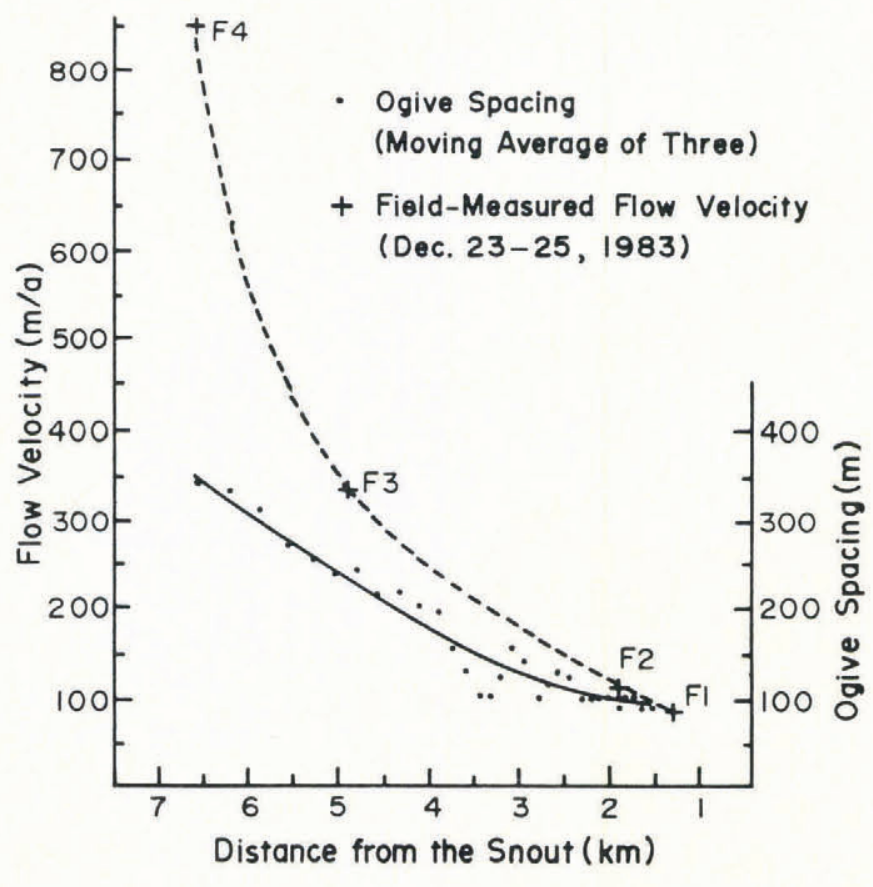

Fig.3. Ogive spacing vs. distance from the snout. Field data superimposed.

mean, annual, surface-flow speed at points. Since we measured surface-flow rates at several points in the field by triangulation, using stakes and a Wild T2 theodolite in December, 1983 (Naruse 1985), these data were superimposed on the figure. Seasonal variation of the flow rate in temperate glaciers is considerable (Elliston 1962) and the basal slip during the summer months contributes to the flow (Haefeli 1966). Consequently, the data at points F1, $\mathrm{F} 2$, and $\mathrm{F} 3$ can be regarded as in close agreement with those deduced from the ogive spacings. However, a large discrepancy is present at the point F4, in which the field data give a value more than double the ogive spacing. This may indicate a considerable amount of basal slip, during the summer, at the upper reach.

\section{Crevasses}

Numerous crevasses are distributed over the glacier below the ice falls. They can be classified into three patterns. The first pattern is observed below the base of icefall B-2. They are formed by the stress caused by a sharp change in the surface slope. The second pattern is found along the left and right margins of the glacier. Most of these crevasses run obliquely from the side toward the middle and up the glacier and are slightly convex in the downward direction. This pattern indicates the typical condition of glacier dynamics, due to the effects of shear stress exerted by the valley walls, as well as compressive stress along the flow (Nye 1952). The third pattern shows heavily undulating surfaces like "seracs", which are prominent in the southern half of the glacier, near the snout. In the vicinity of the snout, ice bodies are not so active, but rather stagnant, and these seracs are considered to be relics of old crevasses, formed in the upper region and then deformed by the melting of ice walls of crevasses.

\section{CONCLUSIONS}

It was shown that, even with this type of photography, i.e., near-vertical, taken with a hand-held, non-metric, $6 \mathrm{x}$ $6 \mathrm{~cm}$-format camera, reasonably accurate information on planimetry and relative height of the glacier structure and morphology can be efficiently obtained.

This type of survey and mapping is very simple and handy, with a minimal cost and is probably applicable to other glaciers of comparable size.

\section{ACKNOWLEDGEMENTS}

This work was carried out in the summer of 1983-84, as part of the "Glaciological Research Project in Patagonia", funded by the Japanese Ministry of Education, Science, and Culture (project nos. 58041045 and 59043040).

\section{REFERENCES}

Aniya $\mathrm{M}$, Enomoto $\mathrm{H}$ In press Recent glacier variations in the Patagonia northern icefield. Transactions of Japanese Geomorphological Union

Elliston G R 1962 Seasonal changes of speed in temperate valley glaciers. Journal of Glaciology 4(33): 289

Haefeli R 1966 Some notes on glacier mapping and ice movement. Canadian Journal of Earth Sciences 3(6): 863-876

Konecny G 1966 Applications of photogrammetry to surveys of glaciers in Canada and Alaska. Canadian Journal of Earth Sciences 3(6): 783-798

Lliboutry L, Reynaud L 1981 "Global dynamics" of a temperate valley glacier, Mer de Glace, and past velocities deduced from Forbes' band. Journal of Glaciology 27(96): 207-226

Naruse R 1985 Flow of Soler Glacier and San Rafael Glacier. In Nakajima C (ed) Glaciological studies in Patagonia northern icefield, 1983-1984. Nagoya, Japanese Society of Snow and Ice. Data Center for Glacier Research: $64-69$

Nye J F 1952 The mechanics of glacier flow. Journal of Glaciology 2(12): $82-93$ 